\title{
Impacting the teaching culture: Role of the department and the software tools
}

\author{
Minha R. Ha and Alidad Amirfazli \\ Departmental of Mechanical Engineering, York University \\ minhareo@yorku.ca
}

\begin{abstract}
Establishing a culture of teaching excellence among faculty with limited prior instructional training raises both practical and philosophical challenges. This paper argues that the departmental unit plays a critical role in setting the conditions necessary for faculty engagement, and that multiple strategies can be coordinated to target change in the teaching norms. The paper introduces the Integrated Course Design and Documentation (ICDD) project at the Department of Mechanical Engineering, York University. The ICDD project demonstrates several of our approaches to effecting change in individual behaviour towards studentcentered pedagogy. They include: (1) making the solution easy for the faculty; (2) making the solution a stand-alone resource that the faculty themselves can develop over time; (3) speaking the language of the faculty (relevance, contextualization); and (4) providing the social, organizational, and practical support for faculty to make the transition. Overall, we argue that any effort to create and sustain change must be multi-faceted, and must include: enabling the instructors as the key agents of change; promoting collaboration among faculty; lowering practical barriers to change by developing technical, administrative, and educational resources that are fit to the local context.
\end{abstract}

\section{Keywords: Teaching culture change; Faculty development; Software solution}

\section{INTRODUCTION}

Involvement of multiple stakeholders are required in the efforts to ensure the quality of undergraduate engineering programs. Examples abound in the engineering schools in Ontario, where departments, Faculty administration, teaching and learning centres, and industry have collaborated in various capacities to improve student learning. The recent accreditation requirements have also given great impetus to explore creative strategies to: (1) shift the teaching culture towards student-centred learning; (2) to make evidence- based decisions in teaching and program evaluation; and (3) to bring about various intervention and improvement strategies.

Nevertheless, each individual instructor is the key, necessary agent in developing, contextualizing, and implementing teaching strategies in every course. Instructor development becomes, therefore, a critical aspect of the program improvement strategies. This does not imply that instructors are the source of problems in the quality of engineering education. Rather, the attempt is to acknowledge that the instructors bear the greatest burden on ensuring the success of departmental and Faculty-wide strategies, or requirements by external bodies. Therefore, the same organizational units must take on the responsibility of supporting instructor transition, and addressing the existing barriers [1], [4], [6], [9].

In order to support the faculty transition, one needs to take into account instructor habits, needs, constraints, as well as strengths. In the context of many engineering departments, there is a mix of research-focused, teachingfocused, and/or service focused faculty members. There are also those who have a more even-handed outlook over all three functions of service, teaching, and research. Some have developed mature habits in their current setting; others have freshly joined the department. Below are five common challenges to establishing best teaching practices:

1. Instructor as an educational expert: There is a general lack of prior training in instructional skills or pedagogy. Moreover, Engineering education is also becoming more multidisciplinary in its requirements, outside engineers' fields of training. Classroom engagement and assessment are both pertinent issues.

2. Weak connection to the body of knowledge in engineering education: Educational literature may remain largely inaccessible, and there lacks wellestablished models of the learning process in engineering. This significantly affects the instructors' ability to review their own understanding of student 
learning, and also to conduct evidence-based evaluation of teaching effectiveness [2].

3. Barriers to engaging in teaching improvement behavior: Course design is done ad hoc in many occasions due to heavy (or ever increasing) workload and limited or diminishing resources. There are limited opportunities to discuss pedagogical design, and even less opportunities to receive constructive feedback on teaching tasks, or rewards. There is a level of anxiety or reluctance to receive additional tasks.

4. Increasing demand for data management: In order to do program accounting, prepare for accreditation review, and satisfying other university policies and procedures, multiple reporting mechanisms exist to collect data from the instructors. Inconsistent documentation and unclear roles around data collection, management, and analysis make it difficult for instructors to effectively navigate or engage in the required procedures.

5. Closing the loop to prompt change in the teaching behavior: For all the above efforts to be valuable to the instructors and the departmental unit, there must be effective follow-up procedures to review the data and put forward actionable recommendations. It is also important to help instructors develop informed expectations about the learners, which inevitably shapes their teaching decisions and behavior (Moore et al., 2015). Rewarding ones advancement or recognition in teaching vis-à-vis research or service needs to be in place as well.

All five aspects are interrelated. Increasing workload and decreasing resources (3) can make, for example, accreditation efforts (4) really difficult to connect to real teaching (5). Therefore, efforts to change the teaching culture must be multi-faceted, coordinating between distinct initiatives to address related issues simultaneously. It is unlikely that any single, isolated strategy will succeed [8].

Departments play an important role in fostering and sustaining change in the teaching norms, values, and practices [10]. Departments can coordinate resources and processes otherwise beyond the scope of single instructors; or create implicit and explicit reward structures that can frame teaching as either a valued or a subsidiary aspect of the departmental membership. For example, existing hierarchies or cultural norms may unevenly distribute administrative duties (e.g. committees) and teaching tasks (e.g. large class), creating a range of conflicting reactions and forms of collaboration across faculty. Important department level differences - that influence teacher perception, motivation and behavior - can contribute to the overall effectiveness of any change initiative [7]. The department must address the varied support needs and motivational factors that influence faculty engagement in change.

With the above backdrop, we developed a project around four key principles described in Section 2. The project is called the Integrated Course Design and Documentation (ICDD). The ICDD project has as its first output a set of software tools (ICDD System) that assist faculty. However, the paper will argue that it is the supportive team's engagement around the ICDD System that determine the success of the teaching culture transition. This paper is meant to be an early report on the ideals of the ICDD project, and is mainly drawn its message from experimentation at a preliminary stage in a single engineering department. Nevertheless, this early reporting should not take away from the central message of this paper, i.e. there is an acute need to a practical and instructor centered strategy to affect culture change within a department. And consequently achieve the ideals of student centered learning and quality assurance practices will be exercised by a majority of faculty members and not just a select few as it is the situation in many engineering departments in Canada.

\section{PRINCIPLES OF THE ICDD PROJCT}

\subsection{The solution must be easy for the instructor (answer practical challenges to instructor autonomy)}

Just as teaching should be learner-centred, we believe the faculty change strategy should be instructor-centred. The goal of the ICDD project is not compliance, but of mastery. With the vision of faculty leading teaching innovations and a thriving community within the department, the change strategy should allow scaffolding and gradual increase of competency in the instructors. While facilitating different ways of developing a course or collecting evidence, the solution should give room for instructors to exercise discretion (and creativity) in the application of new knowledge and tools in their practice, to different contexts. The instructors should be equipped to further develop their teaching practices at the individual level, and the department should be equipped to further mature strategies to ensure program quality.

To begin the scaffold for faculty development, the newly introduced behaviour must be "easy" for faculty to engage. The solution should help faculty complete their teaching tasks in a more efficient manner, reducing any redundant (perceived or real) tasks and making teaching tasks more manageable. Software tools are the most appropriate to manage information that otherwise cost instructors time and energy. The ICDD System organizes and provides all relevant information in one place; 
Instructors do not have to navigate or search multiple places to complete teaching and evidence collection tasks. The ICDD System would also structure e.g. course design tasks in a mold that promotes engagement in teaching approaches that are yet unfamiliar to them.

\subsection{The solution must speak the language of its first clients, the engineering faculty (be relevant in the local context)}

The focus of the solution must be brought back to the vision of quality teaching. This means that the practical tasks for instructors in the ICDD System need to be closely connected to explicit teaching philosophies within the department, and that connection needs to be interpreted and negotiated in the everyday language of engineering professors. Here, the theoretical and practical resources from the field of education need to be "translated" in ways communicable (or better yet familiar in everyday parlance) to engineering faculty.

It cannot be stressed enough that, in order for the change strategy to be effective, the change agents need to spend time understanding the existing language and perspectives of the instructors. For example, for a particular setting, the term 'activity' is immediately viewed as an instructional activity (rather than assessment). A 'student feedback survey' evokes anxiety in some instructors (due to its potential relation to tenure and promotion process), and enthusiasm in others (due to its ability to provide a less skewed understanding of student reactions and experiences). In describing the logic of, e.g. instructional design, there are parallels in the engineering design process that help engineers apply the same evidence-based evaluation to their teaching decisions. Faculty members must be consulted and involved in the design, development, and implementation of the solution.

\subsection{The solution must aim for sustaining the impact (community building)}

Establishing a departmental teaching culture is vital to faculty transition, and vice versa; this is so because individual behaviour shapes and is shaped by the local environment of the collective. Interpersonal interactions are opportunities to build, e.g. a common understanding of the teacher role, an accepted range of best practices in teaching and their underlying assumptions, a value system that recognizes or rewards good teaching, and a set of concepts and language required to make sense of teaching strategies and theories [10], [11]. The department is one mid-level unit that facilitates frequent interaction among faculty via formal meetings (shared decision making, shared resources, shared organizational identity) as well as informal contact (often by physical proximity). The department must develop key roles and support purposeful engagement opportunities among faculty.

\section{IMPLMENTATION}

This section reports on early implementation strategy of the principles stated above. The implementation has been done at the Department of Mechanical Engineering at York University.

\subsection{ICDD System Modules}

The first task of the ICDD System was to remove redundancies and reduce complexity in the required teaching tasks. In order to make teaching tasks easier, online modules (dynamic forms designed on Microsoft InfoPath) were created as a one-stop location where instructors can work on their course design and enter their assessment results. While the instructors review all relevant information and make their inputs, these modules are collect and organize all information required for internal and external reports - thereby minimizing the number of documents that each instructor needs to complete, with redundant information.

Four modules help organize teaching tasks before course implementation (Module 1), throughout course implementation (Modules 2 and 3), and towards the completion of the course (Module 4). The four modules focus on, respectively: (1) course design, (2) assessment design, (3) instructional design, and (4) assessment results submission. Each module has a different layout, prompting the user to enter information or files to complete the module (Fig.1).

To reduce the cognitive load on the instructors preparing a course, Module 1 breaks up the tasks into manageable bits, presenting information that the instructor must take into account (e.g. required accreditation units, connection to pre-requisites, approved course learning outcomes) at appropriate steps. Databases were created to organize curriculum information (e.g. accreditation units, pre-requisites, approved course objectives) and all other relevant information (e.g. instructor contacts, teaching assignment records). These databases are populated by administrative staff. ICDD modules retrieve relevant information from these databases, thereby removing delays caused by instructors looking for information from various documents or personnel. Instructors commented that they did not always have such information readily available to them, and were reassured to know that the module would present all pertinent information during course design. Instructors also expressed interest in knowing the previous instructors of a course, accessing their course outlines, and being able to edit and build on previous experience. 
Module 1 also aim to encourage faculty interaction across courses. The module retrieves information on prerequisite or other related courses, and includes questions about prior engagement with their current and prior instructors. Prior engagement is not mandatory, but the collected information gives the department partial information about faculty collaboration on teaching.

Modules 2 and 3 are designed to guide the instructors through rubric development, assessment design, and lesson planning. The modules use locally adapted templates, and archived examples from instructors, to promote the use of best practices. Module 1 also offers general pre-course surveys as adaptable templates, to enable instructors to gauge student motivation and/or preparedness in fundamental concepts. Instructors can address any gaps during their first week of the course, or direct students to appropriate resources.

Module 4 is being designed to enable the teaching assistants (TAs) and course instructors to submit assessment data in a consistent format, in one location. TA training is being planned to build consistency and a deeper understanding in assessment practices, and also to use the module effectively. The department committees will have access (as discussed and approved by all the members of the department) to the assessment data, for quality assurance, program improvement, and/or instructor improvement purposes.

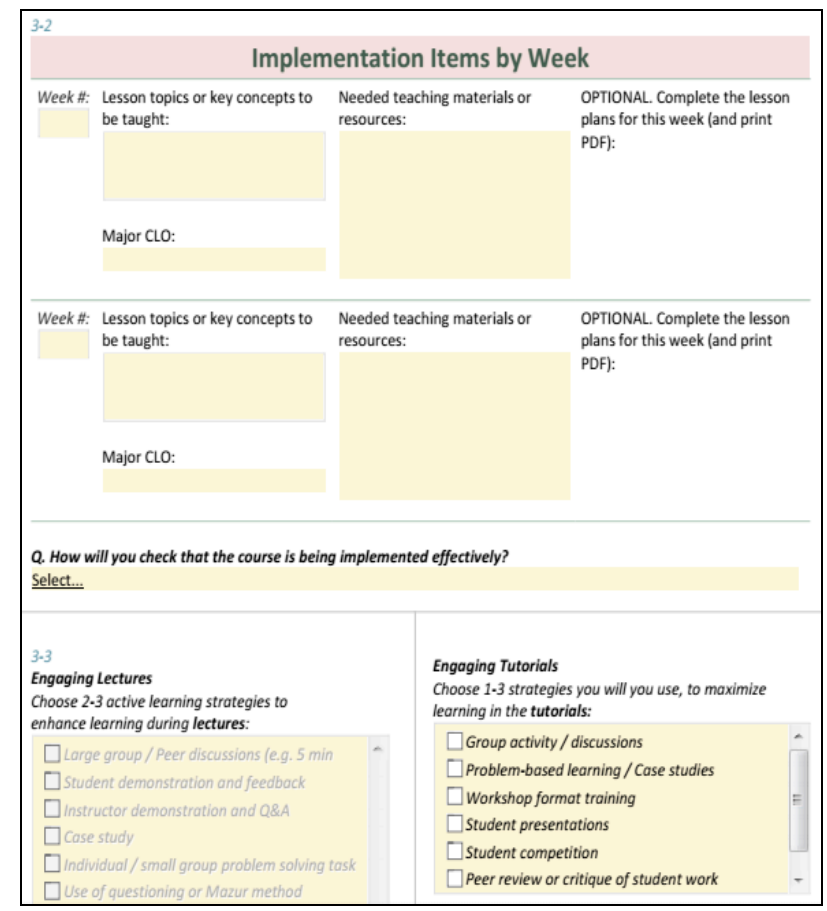

Figure 1. Partial snapshop of ICDD Module 3

\subsection{Building talent and a collective culture}

To accurately assess instructor needs and identify the best resources, the Department hired an educational developer to conduct pilot activities with three instructors on their actual courses (i.e. a design course, a laboratory course, and a traditional lecture-based course). The activities included course design, rubric development, assessment design, lesson planning, and conducting student feedback (mid-course and exit). Based on student feedback, a teaching assistant training was also delivered. The instructors met with the educational developer regularly until they were readily conducting all tasks on their own for different courses. Through these meetings, new templates were developed (e.g. rubrics, assessment data organization), ambiguous terms were clarified, and assumptions (about learners or the learning process) were challenged.

The usefulness of the outputs from the pilot activities, and the increased confidence of instructors in educational development and teaching, established the first level of faculty acceptance of the ICDD project (interest and positive expectation). Pilot educational development activities served as development opportunities for the involved instructors, who became key advisors for the ICDD project. Many elements in the ICDD System were based on the identified needs and feasible ideas developed through these pilot activities.

In order to develop multi-faceted strategies, the Department employed or assigned key project leaders that addressed, including but not limited to: curriculum development, data collection (ICDD System), accreditation policies and procedures, and data analysis. Because of the interdependent nature of these projects, the project leads began meeting together on a regular basis. This collaboration greatly increased the coherence of the four projects, and continues to improve the relevance, usability, and internal communication between the four projects.

The department leadership should played a key role in creating connections among colleagues through related projects, and for organizing the initial meetings (i.e. departmental meetings, ICDD project workshops, and the departmental retreat) that set the tone for ongoing collaborations. In these formal meetings, the interactions between faculty members gave rise to informal conversations about the coordination of assessments between multiple courses, evaluating the connection between pre-requisites and related courses across program levels, textbook selection, the organization of learning outcomes within streams of courses, and other pertinent educational topics. Faculty members identified and challenged their own common misconceptions or myths about assessment and learners (i.e. assessment is 
completely objective; students need to be monitored and graded for uniformity). A common language as a result was established that facilitated discussions on teaching and learning.

Ongoing feedback from grassroots level (and not just Faculty administration) to educational developer has been crucial for: (1) relevance and (2) usability of the ICDD System. Workshops and presentations generated faculty feedback, which included negotiating a common understanding of the ICDD project: its inputs and outputs; the interaction between distinct responsibilities of the instructors, administrators, and the software; the intended impact and use of the data being collected. These discussions helped establish a common vision for program quality (e.g. effective procedures, common understanding of evaluation criteria, supportive relationship between the project leaders and instructors) on a department wide level. Instructors also actively contributed detailed ideas for the ICDD System, including: an approval process for course design, an archival system for documents, a set of questions pertaining to faculty interaction, and tools for gauging student preparedness for the courses.

\section{RESULTS AND DISCUSSION}

The ICDD project aims to promote change in instructor behaviour by engaging them in facilitated course design and data collection tasks. Anecdotally, it was important to have a clear balance between the practicality and the meaningfulness of the ICDD modules, to maintain the connection between teaching tasks and teaching philosophy. Any bias towards convenience (just easy, no significance to teaching behaviour) or theoretical ideals (lacking consideration of real constraints) would have made the ICDD modules disconnected from the actual teacher development.

An unexpected anecdotal finding from the ICDD project processes so far was the interconnectedness between solving a practical challenge to teaching, and solving a philosophical challenge. The discussion around the purposes and uses of the software tools has prompted open debates on the purpose of learning evidence, the logic behind assessment design, the appropriate uses and contexts of rubrics, the issues of privacy and anonymity in student feedback, and so on. The goals of using the ICDD modules were also negotiated, until a consensus was built around why the instructors will be using the tools, and what they will expect as the outcomes. Faculty norm was being established, e.g. adhering to approved course learning outcomes, upholding collectively established procedures that affect the curriculum, sharing course materials to enable continuity and improvement. In other words, instructor ownership within the supportive local environment was creating the changes in instructor perception and behaviour that the ICDD System also aimed to support (see Appendix I for our expected outcomes on teacher behaviour).

To facilitate change in instructor behaviour, the ICDD System has to be accepted and used effectively by the instructors. Instructors welcomed the efforts to make the solution work for them, making the software tools easy to use (Section 2.1), and meaningful to their job as teachers (Section 2.2). Frequent instructor feedback, trial runs, and pilot activities helped develop the ICDD modules in a way that made sense to the instructors, because they were closely involved in creating what would help them succeed as teachers. Over the course of two academic terms, the ICDD project has prompted instructors to develop their courses with greater constructive alignment. The ICDD System garnered enthusiasm and increasing faculty readiness for formal implementation (in preparation for the Fall 2016 courses).

The changing form and quality of faculty interaction can serve as indicators of the changing teaching culture at the department (Section 2.3). It is believed that the ICDD project has contributed to lowering anxiety and encouraging participation in teaching-related activities and welcoming the student centered and documentation requirements as articulated by the recent accreditation changes. At the present, faculty members are actively discussing the curriculum, alignment between courses, and the relationship between various teaching tasks and the program review procedures. Discussion topics have evolved - from data management concerns and reporting efficiencies, emphasis has moved to the effective use of data, access to educational resources, and integration between various program-level activities within the department. Majority of the instructors are collaborating with one another on assessments, program accounting, managing student workload, preparation for accreditation, and other program level activities. Newly identified needs and interests are informing he ICDD System development.

There are several questions still to be answered for the ICDD project:

1. First issue deals with how technology shapes thinking and behaviour. How do the ICDD modules promote learning, thinking, and creativity of teachers? Do the modules result in routine behavior that lacks critical reflection? Can the software tools adapt to the growing competence of the instructors (and diversifying needs of the curriculum), and avoid attempts to build a one-size-fits-all solution?

2. Second theme deals with the translation between qualitative evaluation criteria (i.e. of graduate 
attributes) and the quantitative grading results. Collaboration between project leaders led to a robust discussion on the development of assessment criteria, and the interpretation of grading results. Do the ICDD modules encourage critical examination of the grading procedures, or does it promote taking the results for granted? What kind of support must be provided to the faculty in their use of proper assessment methods for diverse types of learning outcomes?

These are larger issues that require greater engagement with the educational research literature. Partnership across departments may greatly benefit answering these questions, as engineering programs may share similar challenges while offering a greater network of resources through the members of the departments.

\section{CONCLUSION}

Overall, the ICDD project has had early success in increasing instructor expertise in teaching, engaging them in teaching development activities, and improving the data management mechanisms. Procedures are being developed to facilitate data analysis, which will help instructors and the department make important decisions to improve program quality.

Department administration played a central role to implementing an instructor-centred model of change. Key roles were developed to mobilize collaboration, create a shared vision, and enact newly developed policy and procedures. The ICDD System served as a platform to make teaching philosophies and assumptions explicit, which created opportunities to build a common language to facilitate meaningful discussions around teaching and learning. The result has been a ground-up ownership of the change strategies, and an integration of the various projects as facilitated by faculty and staff. Support is needed for both practical strategies and theoretical development in engineering education, in ways that encourage capacity-development at the individual and departmental levels.

\section{Acknowledgments}

We would like to acknowledge the input from all instructors in the Department of Mechanical Engineering contributing to the ICDD project, and also for partial funding from the NSERC Design Chair program at York University.

\section{References}

[1] Biggs, J. (2001). The reflective institution: Assuring and enhancing the quality of teaching and learning 1. Higher Education, $41, \quad 221-238$. http://doi.org/10.1023/a:1004181331049

[2] Borrego, M., \& Henderson, C. (2014). Increasing the use of evidence-based teaching in STEM higher education: A comparison of eight change strategies. Journal of Engineering Education, 103(2), 220-252. http://doi.org/10.1002/jee.20040

[3] Caldwell, S. E., \& Mays, N. (2012). Studying policy implementation using a macro, meso and micro frame analysis: the case of the Collaboration for Leadership in Applied Health Research \& Care (CLAHRC) programme nationally and in North West London. Health Research Policy and Systems, 10(1), 32-40. http://doi.org/10.1186/1478-4505-10-32

[4] Ingvarson, L., Meiers, M., \& Beavis, A. (2005). Factors affecting the impact of professional development programs on teachers' knowledge, practice, student outcomes \& efficacy. Education Policy Analysis Archives, 13(10), 1-28.

[5] Lattuca, L. R., Bergom, I., \& Knight, D. B. (2014). Professional development, departmental contexts, and use of instructional strategies. Journal of Engineering Education, 103(4), 549-572. http://doi.org/10.1002/jee.20055

[6] Olsson, T., \& Roxå, T. (2013). Assessing and rewarding excellent academic teachers for the benefit of an organization. European Journal of Higher Education, 3(1), 40-61. http://doi.org/10.1080/21568235.2013.778041

[7] Roxå, T., \& Mårtensson, K. (2014). Higher education commons - a framework for comparison of midlevel units in higher education organizations. European Journal of Higher Education, 4(September 2015), 303-316. http://doi.org/10.1080/21568235.2014.924861

[8] Roxå, T., Martensson, K., \& Alveteg, M. (2011). Understanding and influencing teaching and learning cultures at university: A network approach. Higher Education, 62(1), 99111. http://doi.org/10.1007/s10734-010-9368-9

[9] Stes, A., Clement, M., \& Van Petegem, P. (2007). The Effectiveness of a Faculty Training Programme: Long-term and Institutional Impact. International Journal for Academic Development, 12(2), 99-109. http://doi.org/10.1080/13601440701604898

[10] Trowler, P., Fanghanel, J., \& Wareham, T. (2005). Freeing the chi of change: the Higher Education Academy and enhancing teaching and learning in higher education. Studies in Higher Education, 30(4), 427-444. http://doi.org/10.1080/03075070500160111

[11] Trowler, P. R., \& Cooper, A. (2002). Teaching and learning regimes: Implicit theories and recurrent practices in the enhancement of teaching and learning through educational development programmes. Higher Education Research \& Development, 21(3), 221-240. http://doi.org/10.1080/0729436022000020742 
Appendix I. Theory of Change Framework for Instructor Behaviour Using the ICDD System

\begin{tabular}{|c|c|c|c|}
\hline Situation & ICDD Project Goals & Desired Instructor Response & Long Term Impact \\
\hline $\begin{array}{l}\text { Lack of prior training in } \\
\text { instructional skills or } \\
\text { pedagogy (everyone } \\
\text { teaches differently } \\
\text { Lack of opportunity to } \\
\text { discuss pedagogical } \\
\text { design and resources } \\
\text { Heavy workload and limited } \\
\text { resources in designing } \\
\text { courses and exchanging }\end{array}$ & $\begin{array}{l}\text { Facilitate teaching tasks in } \\
\text { manageable chunks } \\
\text { Provide a platform to design } \\
\text { assessments (e.g. } \\
\text { quizzes, assignments, } \\
\text { project instructions) } \\
\text { Provide access to the } \\
\text { internal archive and } \\
\text { allow for modification }\end{array}$ & $\begin{array}{l}\text { Organize and develop course } \\
\text { materials in timely, and } \\
\text { thoughtful ways } \\
\text { Communicate information } \\
\text { promptly and consistently to } \\
\text { students } \\
\text { Implement courses as } \\
\text { planned/designed; make } \\
\text { informed decisions for course } \\
\text { improvement } \\
\text { Generate and build educational } \\
\text { materials }\end{array}$ & $\begin{array}{l}\text { Effective course } \\
\text { design and } \\
\text { implementation } \\
\text { Lasting student } \\
\text { learning } \\
\text { outcomes }\end{array}$ \\
\hline $\begin{array}{l}\text { feedback (ad hoc, not } \\
\text { process based) } \\
\text { Anxiety or reluctance to } \\
\text { additional tasks to } \\
\text { already overwhelming } \\
\text { number of deliverables } \\
\text { (resistance to new tasks, } \\
\text { pessimism, barrier to } \\
\text { change in behaviour) } \\
\text { Inconsistent documentation, } \\
\text { no single archive for } \\
\text { easy retrieval of } \\
\text { information to be } \\
\text { reviewed, difficult for } \\
\text { inctructor }\end{array}$ & $\begin{array}{l}\text { Develop program-level } \\
\text { databases (e.g. teaching } \\
\text { assignments, course } \\
\text { learning outcomes, } \\
\text { approved course } \\
\text { proposals) } \\
\text { Create a common platform } \\
\text { that retrieves and } \\
\text { presents information } \\
\text { needed for course design } \\
\text { Include a review and an } \\
\text { approval process }\end{array}$ & $\begin{array}{l}\text { Discussing course design and } \\
\text { learning outcomes across } \\
\text { levels and between courses } \\
\text { within each level } \\
\text { Co-create the standards and } \\
\text { procedures for course design, } \\
\text { assessment, course policies, } \\
\text { and documentation. } \\
\text { Engage in coordinating decisions } \\
\text { appropriate for each stream of } \\
\text { courses } \\
\text { Adhere to approved course } \\
\text { proposals and curriculum map }\end{array}$ & $\begin{array}{l}\text { Integration and } \\
\text { alignment } \\
\text { between courses } \\
\text { for strengthened } \\
\text { learning } \\
\text { outcomes } \\
\text { through the } \\
\text { program }\end{array}$ \\
\hline $\begin{array}{l}\text { course information } \\
\text { Lack of systematic evidence } \\
\text { collection mechanism, } \\
\text { needed for evidence- } \\
\text { based program } \\
\text { improvement } \\
\text { Difficulty of doing program }\end{array}$ & $\begin{array}{l}\text { Compile information for } \\
\text { required documentation, } \\
\text { i.e. course binder } \\
\text { materials, evidence of } \\
\text { graduate attributes } \\
\text { Effective evidence collection } \\
\text { process for learning } \\
\text { outcomes } \\
\text { Provide tools for collecting } \\
\text { student feedback }\end{array}$ & $\begin{array}{l}\text { Participate in systematic program } \\
\text { improvement and review } \\
\text { processes } \\
\text { Monitor program delivery in a } \\
\text { prompt way } \\
\text { Examine the plans, actual delivery, } \\
\text { and the results of courses } \\
\text { Review and respond to student } \\
\text { learning needs and feedback }\end{array}$ & $\begin{array}{l}\text { Effective } \\
\text { responsiveness of } \\
\text { the department's } \\
\text { educational } \\
\text { strategies to } \\
\text { emerging student } \\
\text { needs }\end{array}$ \\
\hline $\begin{array}{l}\text { Lack of prompt feedback on } \\
\text { and monitoring of the } \\
\text { actual teaching } \\
\text { behaviour }\end{array}$ & $\begin{array}{l}\text { Translation and clarification } \\
\text { of key educational } \\
\text { concepts } \\
\text { Provide example assessment } \\
\text { items associated with } \\
\text { particular graduate } \\
\text { attributes or learning } \\
\text { objectives } \\
\text { Provide examples of active } \\
\text { learning strategies }\end{array}$ & $\begin{array}{l}\text { Faculty participation in } \\
\text { conferences or educational } \\
\text { research } \\
\text { Faculty utilization of literature } \\
\text { from educational research / } \\
\text { best practices } \\
\text { Incorporate best practice strategies } \\
\text { into daily teaching }\end{array}$ & $\begin{array}{l}\text { Sustained and } \\
\text { continued } \\
\text { capacity building } \\
\text { of ME instructors } \\
\text { to engage in } \\
\text { educational } \\
\text { development and } \\
\text { research }\end{array}$ \\
\hline
\end{tabular}

